\title{
Impact of interstitial lung disease on postoperative morbidity and 90-day mortality after pulmonary resection
}

\author{
Weipeng Shao ${ }^{1}$, Jingjing Huang ${ }^{2}$, Hongxiang Feng ${ }^{2}$, Hongliang Sun ${ }^{3}$, Yanhong Ren ${ }^{4}$ Xiaowei Wang ${ }^{5}$, \\ Zhenrong Zhang ${ }^{2}$, Deruo Liu ${ }^{1}$ \\ ${ }^{1}$ Department of General Thoracic Surgery, Peking University China-Japan Friendship School of Clinical Medicine and China-Japan Friendship \\ Hospital, Beijing 100029, China; ${ }^{2}$ Department of General Thoracic Surgery, ${ }^{3}$ Department of Radiology, ${ }^{4}$ Department of Respiration, ${ }^{5}$ Department of \\ Pathology, China-Japan Friendship Hospital, Beijing 100029, China \\ Contributions: (I) Conception and design: W Shao, Z Zhang, D Liu; (II) Administrative support: D Liu; (III) Provision of study materials or patients: \\ All authors; (IV) Collection and assembly of data: W Shao, Z Zhang; (V) Data analysis and interpretation: W Shao, Z Zhang, H Feng; (VI) \\ Manuscript writing: All authors; (VII) Final approval of manuscript: All authors. \\ Correspondence to: Deruo Liu. Department of General Thoracic Surgery, Peking University China-Japan Friendship School of Clinical Medicine and \\ China-Japan Friendship Hospital, No. 2, Yinghua, East Rd., Beijing 100029, China. Email: deruoliu@163.com; Zhenrong Zhang. Department of \\ General Thoracic Surgery, China-Japan Friendship Hospital, No. 2, Yinghua, East Rd., Beijing 100029, China. Email: doctor_zzr@126.com.
}

Background: To evaluate the effect of interstitial lung disease (ILD) on postoperative morbidity and mortality in pulmonary resection and identify the factors of AE-ILD.

Methods: We retrospectively analyzed 1,309 patients underwent pulmonary operation between January 2010 and January 2018 in our hospital. Clinical data including age, sex, history of chronic obstructive pulmonary disease (COPD), smoking history, smoking index, American Society of Anesthesiologists (ASA) classification, Charlson comorbidity index (CCI), forced expiratory volume in $1 \mathrm{~s}$ (FEV1) \% predict, surgical procedure, video-assisted thoracoscopic surgery (VATS) or not, intraoperative blood transfusion, anesthesia time, operation time/one-lung ventilation time, blood loss, histology, postoperative morbidity, 90-day mortality, onset of acute exacerbation of ILD (AE-ILD), and postoperative stay were collected and analyzed. Results: There were 97 (7.4\%) and 1,212 (92.6\%) patients in the ILD and non-ILD groups, respectively. AE-ILD occurred in 6 patients $(0.5 \%)$, with a mortality of $83.3 \%$, and was the leading cause of 90 -day mortality $(55.6 \%)$. Age $(\mathrm{P}<0.001)$ was an independent risk factor for ILD. There were 6 and 91 patients in the AE-ILD and non-AE-ILD groups, respectively. ASA classification $(\mathrm{P}=0.038)$ were independent risk factors for AE-ILD. Multivariate regression analysis identified that the sex $(\mathrm{P}=0.003), \mathrm{ILD}(\mathrm{P}<0.001), \mathrm{COPD}$ $(\mathrm{P}=0.007)$, surgical procedure $(\mathrm{P}<0.001)$, blood loss $(\mathrm{P}<0.001)$, CCI $(\mathrm{P}=0.049)$ were independent risk factors for postoperative morbidity. ILD $(\mathrm{P}=0.001)$ and postoperative morbidity $(\mathrm{P}=0.003)$ were independent risk factors for 90-day mortality in multivariate analysis.

Conclusions: Patients with ILD had a higher incidence of postoperative morbidity and 90-day mortality. ASA classification was an important influencing factor for AE-ILD. Based on the obvious postoperative morbidity and mortality, special attention and management should be given to ILD patients.

Keywords: Interstitial lung disease (ILD); pulmonary resection; acute exacerbation of interstitial lung disease; morbidity; 90-day mortality

Submitted Jun 25, 2019. Accepted for publication Dec 17, 2019.

doi: $10.21037 /$ tcr.2019.12.88

View this article at: http://dx.doi.org/10.21037/tcr.2019.12.88 


\section{Introduction}

Interstitial lung disease (ILD) is a group of diseases with diffuse alveolar chronic inflammation and interstitial fibrosis as the main pathological characteristics, it mainly occurs in the elderly individuals and had no specific predisposing factors (1). Generally, ILD includes idiopathic pulmonary fibrosis, connective tissue disease-related interstitial pulmonary disease, and sarcoidosis (2). The symptoms and signs of many ILD patients lack specificity. The etiology of ILD remains unclear, the history of long-term smoking or some occupational factors might contribute to the occurrence of $\operatorname{ILD}(3,4)$. Surgical operation is the primary therapeutic method for ILD patients complicated with lung cancer or suspected lung cancer. However, acute exacerbation of ILD (AE-ILD), as a disastrous postoperative complication, could dramatically increase postoperative mortality in these patients $(5,6)$. Approaches to decrease postoperative mortality and preclude the occurrence of AE-ILD has drawn much attention (5,7-9). This study attempted to clarify the impact of ILD on postoperative morbidity and 90-day mortality of patients undergoing pulmonary resection.

\section{Methods}

The patients underwent surgery after providing informed consent, and the requirement for the individual consent of patients whose records were evaluated was waived because they were de-identified in the study. The study was approved by institutional ethics board of China-Japan Friendship Hospital (No. 2018-13-K08). Information about preoperative patient characteristics, disease status, surgical procedures, postoperative morbidity, pathological findings and treatment was collected.

We retrospectively analyzed 1,309 patients who underwent pulmonary surgery in our hospital between January 2010 and January 2018.

Preoperative, intraoperative, and postoperative data were collected for all patients, including age $(\geq /<65)$, sex (male/female), history of chronic obstructive pulmonary disease (COPD), smoking history, smoking index, American Society of Anesthesiologists (ASA) classification, Charlson comorbidity index (CCI), forced expiratory volume in $1 \mathrm{~s}$ (FEV1) \% predict, surgical procedure, videoassisted thoracoscopic surgery (VATS), intraoperative blood transfusion, anesthesia time, operation time/onelung ventilation time, blood loss, histology, postoperative morbidity [pulmonary leakage ( $>1$ week), pleural effusion (second-time thoracic puncture), pulmonary infection (fever and culture positive), chylothorax (whether somatostatin therapy is effective)], 90-day mortality, onset of AE-ILD, and postoperative stay.

According to the guidelines drafted by the American Thoracic Society (ATS), the European Respiratory Society (ERS), the Japanese Respiratory Society (JRS) and the Latin American Thoracic Society (ALAT), ILD could be divided into two groups according to the CT findings: (I) usual interstitial pneumonia (UIP): this group was characterized by the presence of basal-dominant reticular opacities and a predominantly basal and subpleural distribution of honeycomb lesions with multiple equal-sized cystic lesions of 2 to $10 \mathrm{~mm}$ in diameter with a thick wall. (II) non-UIP: This group was characterized by the presence of basalpredominant ground-glass opacities and infiltrative shadows inconsistent with UIP patterns (6).

AE-ILD caused by pulmonary resection was defined based on the following criteria: (I) dyspnea of unknown origin within 30 days; (II) decrease in $\mathrm{PaO}_{2}$ by at least $10 \mathrm{mmHg}$ under same respiratory condition; (III) newly found ground glass shadow or diffuse alveolar injury in the background of UIP according to chest CT scan; (IV) no evidence of pulmonary infection; (V) exclusion of alternative causes, such as cardiac failure, pulmonary embolism, or other identifiable causes of lung injury. Exacerbations that occurred from 31 days onward were defined as chronic exacerbations (10). The primary outcome of the study was 90-day mortality (death from any cause within 90 days postoperation).

\section{Statistical analysis}

Statistical analysis was performed with SPSS 24.0 software (SPSS, Inc., Chicago, IL, USA). All data were presented as median \pm quartile deviation. Continuous variables were compared with the independent sample $t$-test. Categorical and dichotomic variables were compared by $\chi^{2}$ test and Fisher's exact test, respectively. All $\mathrm{P}$ values were 2 -sided, and the statistical significance level was set at less than 0.05 .

\section{Results}

A total of 1,309 patients who underwent pulmonary resection were reviewed. The median age of the patients was 58.9 years, $755(57.7 \%)$ of 1,309 patients were male, and 508 (38.8\%) of 1,309 patients had a smoking history. Among these patients, 97 (7.4\%) patients were 
Table 1 Patient characteristics

\begin{tabular}{|c|c|c|c|}
\hline Variables & ILD (n=97) & $\begin{array}{l}\text { Non-ILD } \\
(n=1,212)\end{array}$ & $\mathrm{P}$ \\
\hline Age & & & $<0.001$ \\
\hline$\geq 65$ & 54 & 370 & \\
\hline$<65$ & 43 & 842 & \\
\hline Sex & & & 0.053 \\
\hline Male & 65 & 690 & \\
\hline Female & 32 & 522 & \\
\hline COPD & & & 0.859 \\
\hline Yes & 10 & 132 & \\
\hline No & 87 & 1,080 & \\
\hline Smoking history & & & 0.043 \\
\hline Yes & 47 & 461 & \\
\hline No & 50 & 751 & \\
\hline Smoking index (>400) & & & 0.031 \\
\hline Yes & 33 & 293 & \\
\hline No & 64 & 919 & \\
\hline Lobectomy & & & 0.532 \\
\hline No & 31 & 351 & \\
\hline Yes & 66 & 861 & \\
\hline Approach & & & 0.135 \\
\hline VATS & 60 & 846 & \\
\hline VAMT & 23 & 258 & \\
\hline OPEN & 14 & 108 & \\
\hline Blood transfusion & & & 0.032 \\
\hline Yes & 13 & 89 & \\
\hline No & 84 & 1,123 & \\
\hline ASA classification & & & 0.005 \\
\hline $\mathrm{I} / \mathrm{II}$ & 76 & 1,069 & \\
\hline III/IV & 21 & 143 & \\
\hline Histology & & & 0.052 \\
\hline Malignant & 80 & 891 & \\
\hline Benign & 17 & 321 & \\
\hline Postoperative morbidity & & & $<0.001$ \\
\hline Yes & 35 & 226 & \\
\hline No & 62 & 986 & \\
\hline
\end{tabular}

Table 1 (continued)
Table 1 (continued)

\begin{tabular}{|c|c|c|c|}
\hline Variables & ILD $(n=97)$ & $\begin{array}{l}\text { Non-ILD } \\
(n=1,212)\end{array}$ & $\mathrm{P}$ \\
\hline Death within 90 days & & & $<0.001$ \\
\hline Yes & 5 & 4 & \\
\hline No & 92 & 1,208 & \\
\hline FEV1 of predicted (\%) & $\begin{array}{c}77.7 \\
{[73.12-79.95]}\end{array}$ & $\begin{array}{c}78.1 \\
{[74.51-80.66]}\end{array}$ & 0.452 \\
\hline Anaesthesia time (min) & 260 [175-320] & 250 [190-310] & 0.955 \\
\hline Operating time (min) & 200 [120-267.5] & 195 [130-255] & 0.703 \\
\hline Blood loss (mL) & 150 [50-300] & $100[50-250]$ & 0.427 \\
\hline $\begin{array}{l}\text { Postoperative stay } \\
\text { (days) }\end{array}$ & 9 [8-13.5] & 8 [7-12] & 0.038 \\
\hline $\mathrm{CCl}$ & 3 [2-4] & $3[2-4]$ & $<0.001$ \\
\hline \multicolumn{4}{|c|}{$\begin{array}{l}\text { ILD, interstitial lung disease; COPD, chronic obstructive } \\
\text { pulmonary disease; VATS, video assisted thoracoscopic surgery; } \\
\text { VAMT, video-assisted minithoracotomy; ASA, American Society } \\
\text { of Anesthesiologists; FEV1, forced expiratory volume in } 1 \mathrm{~s} \text {; CCI } \\
\text { Charlson comorbidity index. }\end{array}$} \\
\hline
\end{tabular}

diagnosed with UIP according to high resolution computed tomography/computed tomography (HRCT/CT).

Based on CT characteristics, the enrolled patients were classified into the ILD group and non-ILD group. The clinical data of all patients are shown in Table 1. In the ILD group, $54(55.7 \%)$ patients were no younger than 65 years old, $65(67.0 \%)$ patients were male, $10(10.3 \%)$ patients had combined COPD, 47 (48.5\%) patients had a smoking history and $33(34.0 \%)$ patients had a smoking index greater than 400, 13 (13.4\%) patients received intraoperative blood transfusion. Seventy-six (78.4\%) patients were classified as I and II by ASA, 80 (82.5\%) patients were diagnosed with malignant tumors, $35(36.1 \%)$ patients had postoperative complications, and 5 (5.2\%) patients died within 90 days. The average days of hospitalization were 9 (IQR, 8-13.5) days and $8(\mathrm{IQR}, 7-12)$ days $(\mathrm{P}=0.038)$ in the ILD group and non-ILD group, respectively. The CCI was 3 (IQR, 2-4) in 2 groups $(\mathrm{P}<0.001)$. Age $(\mathrm{P}<0.001)$ was an independent risk factor for ILD in multivariate analysis (Table 2).

According to AE-ILD status, 97 patients with ILD were divided into AE-ILD group and non-AE-ILD group. Multivariate regression analysis further identified that ASA classification $(\mathrm{P}=0.038)$ were independent risk factor of $\mathrm{AE}$ ILD (Table 3 and 4).

All included patients were grouped according to the 
Table 2 Multivariate analysis to identify predictors of interstitial lung disease

\begin{tabular}{lccc}
\hline Variable & OR & $95 \% \mathrm{Cl}$ & $\mathrm{P}$ \\
\hline Age & 2.849 & $1.868-4.347$ & $<0.001$ \\
\hline $\begin{array}{l}\text { ILD, interstitial lung disease; } \\
\text { interval. }\end{array}$
\end{tabular}

Table 3 ILD patient characteristics

\begin{tabular}{|c|c|c|c|}
\hline Variables & AE-ILD $(n=6)$ & $\begin{array}{l}\text { Non-AE-ILD } \\
\quad(n=91)\end{array}$ & $P$ \\
\hline Age (years) & & & 0.325 \\
\hline$\geq 65$ & 5 & 49 & \\
\hline$<65$ & 1 & 42 & \\
\hline Sex & & & 0.173 \\
\hline Male & 6 & 59 & \\
\hline Female & 0 & 32 & \\
\hline COPD & & & 0.222 \\
\hline Yes & 2 & 8 & \\
\hline No & 4 & 83 & \\
\hline Smoking history & & & 0.617 \\
\hline Yes & 4 & 43 & \\
\hline No & 2 & 48 & \\
\hline Smoking index (>400) & & & 1.000 \\
\hline Yes & 2 & 29 & \\
\hline No & 4 & 62 & \\
\hline Lobectomy & & & 1.000 \\
\hline No & 2 & 29 & \\
\hline Yes & 4 & 62 & \\
\hline Approach & & & 0.210 \\
\hline VATS & 4 & 56 & \\
\hline VAMT & 0 & 23 & \\
\hline OPEN & 2 & 12 & \\
\hline Blood transfusion & & & 1.000 \\
\hline Yes & 1 & 12 & \\
\hline No & 5 & 79 & \\
\hline ASA classification & & & 0.024 \\
\hline $\mathrm{I} / \mathrm{II}$ & 2 & 74 & \\
\hline III/IV & 4 & 17 & \\
\hline
\end{tabular}

Table 3 (continued)
Table 3 (continued)

\begin{tabular}{|c|c|c|c|}
\hline Variables & AE-ILD $(n=6)$ & $\begin{array}{c}\text { Non-AE-ILD } \\
\quad(n=91)\end{array}$ & $\mathrm{P}$ \\
\hline Histology & & & 1.000 \\
\hline Malignant & 5 & 75 & \\
\hline Benign & 1 & 16 & \\
\hline Postoperative morbidity & & & 0.002 \\
\hline Yes & 6 & 29 & \\
\hline No & 0 & 62 & \\
\hline Death within 90 days & & & $<0.001$ \\
\hline Yes & 5 & 0 & \\
\hline No & 1 & 91 & \\
\hline FEV1 of predicted (\%) & $\begin{array}{c}76.75 \\
{[57.75-95.75]}\end{array}$ & $\begin{array}{c}77.57 \\
{[67.60-87.54]}\end{array}$ & 0.920 \\
\hline Anaesthesia time (min) & 235 [154-315] & 255 [161-349] & 0.605 \\
\hline Operating time (min) & 187 [111-263] & 215 [61-269] & 0.664 \\
\hline Blood loss (mL) & 226 [40-412] & 218 [68-368] & 0.933 \\
\hline Postoperative stay (days) & 28 [6-50] & $11[4-18]$ & 0.128 \\
\hline $\mathrm{CCl}$ & $4[3-5]$ & $4[3-5]$ & 0.507 \\
\hline \multicolumn{4}{|c|}{$\begin{array}{l}\text { ILD, interstitial lung disease; COPD, chronic obstructive } \\
\text { pulmonary disease; VATS, video assisted thoracoscopic surgery; } \\
\text { VAMT, video-assisted minithoracotomy; ASA, American Society } \\
\text { of Anesthesiologists; FEV1, forced expiratory volume in } 1 \mathrm{~s} \text {; CCl, } \\
\text { Charlson comorbidity index. }\end{array}$} \\
\hline
\end{tabular}

Table 4 Multivariate analysis to identify predictors of AE-ILD

\begin{tabular}{lccc}
\hline Variable & OR & $95 \% \mathrm{Cl}$ & $\mathrm{P}$ \\
\hline ASA & 0.130 & $0.190-0.890$ & 0.038 \\
\hline
\end{tabular}

postoperative morbidity and 90-day mortality. A total of $261(19.3 \%)$ patients had postoperative complications, and $9(0.7 \%)$ patients died within 90 days. Univariate analysis identified that $\operatorname{sex}(\mathrm{P}<0.001)$, ILD $(\mathrm{P}<0.001)$, COPD $(\mathrm{P}<0.001)$, smoking history $(\mathrm{P}=0.026)$, smoking index $(\mathrm{P}=0.004)$, surgical procedure $(\mathrm{P}<0.001)$, VATS $(\mathrm{P}<0.001)$, intraoperative blood transfusion $(\mathrm{P}<0.001)$, histology $(\mathrm{P}=0.001), \mathrm{FEV} 1 \%$ predict $(\mathrm{P}<0.001)$, anesthesia time $(\mathrm{P}<0.001)$, operation time/one-lung ventilation time $(\mathrm{P}<0.001)$, blood loss $(\mathrm{P}<0.001)$, CCI $(\mathrm{P}=0.001)$ were candidate risk factors for postoperative morbidity (Table 5). Multivariate regression analysis further identified male sex 
Table 5 Univariate analysis to identify predictors of postoperative morbidity and 90-day mortality among patients with ILD

\begin{tabular}{|c|c|c|c|}
\hline Variables & $\begin{array}{l}\text { Morbidity/not } \\
(\mathrm{n}=261 / 1,048)\end{array}$ & $\begin{array}{c}90 \text { death/not } \\
(n=9 / 1,300)\end{array}$ & $\mathrm{P}$ \\
\hline \multicolumn{3}{|l|}{ Age (years) } & $0.066 / 0.010$ \\
\hline$\geq 65$ & $97 / 327$ & $7 / 417$ & \\
\hline$<65$ & $164 / 721$ & $2 / 883$ & \\
\hline \multicolumn{3}{|l|}{ Sex } & $<0.001 / 0.376$ \\
\hline Male & $182 / 573$ & $7 / 748$ & \\
\hline Female & $79 / 475$ & $2 / 552$ & \\
\hline \multicolumn{3}{|l|}{ ILD } & $<0.001 /<0.001$ \\
\hline Yes & $35 / 62$ & $5 / 92$ & \\
\hline No & $226 / 986$ & $4 / 1,208$ & \\
\hline \multicolumn{3}{|l|}{ COPD } & $<0.001 / 0.101$ \\
\hline Yes & $45 / 97$ & $3 / 139$ & \\
\hline No & $216 / 951$ & $6 / 1,161$ & \\
\hline \multicolumn{3}{|l|}{ Smoke } & 0.026/0.489 \\
\hline Yes & $117 / 391$ & $5 / 503$ & \\
\hline No & $144 / 657$ & $4 / 797$ & \\
\hline \multicolumn{3}{|c|}{ Smoking index $(>400)$} & $0.004 / 0.081$ \\
\hline Yes & $83 / 242$ & $5 / 321$ & \\
\hline No & $178 / 806$ & $4 / 980$ & \\
\hline \multicolumn{3}{|l|}{ Lobectomy } & $<0.001 / 1$ \\
\hline No & $40 / 342$ & $3 / 379$ & \\
\hline Yes & $221 / 706$ & $6 / 921$ & \\
\hline \multicolumn{3}{|l|}{ Approach } & $<0.001 / 0.221$ \\
\hline VATS & $154 / 752$ & $4 / 902$ & \\
\hline VAMT & $73 / 208$ & $3 / 278$ & \\
\hline OPEN & $34 / 88$ & $2 / 120$ & \\
\hline \multicolumn{3}{|c|}{ Blood transfusion } & $<0.001 / 0.319$ \\
\hline Yes & $34 / 68$ & $2 / 100$ & \\
\hline No & $227 / 980$ & $7 / 1,200$ & \\
\hline \multicolumn{3}{|c|}{ ASA classification } & $0.127 / 0.017$ \\
\hline $\mathrm{I} / \mathrm{II}$ & $221 / 924$ & $5 / 1,140$ & \\
\hline III/IV & $40 / 124$ & $4 / 160$ & \\
\hline \multicolumn{3}{|l|}{ Histology } & $0.001 / 0.529$ \\
\hline Malignant & $214 / 757$ & $8 / 963$ & \\
\hline Benign & $47 / 291$ & $1 / 337$ & \\
\hline
\end{tabular}

Table 5 (continued)
Table 5 (continued)

\begin{tabular}{|c|c|c|c|}
\hline Variables & $\begin{array}{l}\text { Morbidity/not } \\
(n=261 / 1,048)\end{array}$ & $\begin{array}{c}90 \text { death/not } \\
(n=9 / 1,300)\end{array}$ & $P$ \\
\hline \multicolumn{3}{|c|}{ Death within 90 days/morbidity } & $<0.001 /<0.001$ \\
\hline Yes & $8 / 1$ & $8 / 253$ & \\
\hline No & $253 / 1,047$ & $1 / 1,047$ & \\
\hline $\begin{array}{l}\text { FEV1 of } \\
\text { predicted (\%) }\end{array}$ & $\begin{array}{l}76.7[70.85-80.16] / \\
78.29[74.91-80.77]\end{array}$ & $\begin{array}{c}74.1 \\
{[67.5-85.35] /} \\
78.1 \\
{[74.27-80.6]}\end{array}$ & $<0.001 / 0.636$ \\
\hline $\begin{array}{l}\text { Anaesthesia } \\
\text { time (min) }\end{array}$ & $\begin{array}{l}290[230-330] / \\
240[180-303]\end{array}$ & $\begin{array}{c}250 \\
{[205-312.5] /} \\
250 \\
{[190-310]}\end{array}$ & $<0.001 / 0.934$ \\
\hline $\begin{array}{l}\text { Operating } \\
\text { time (min) }\end{array}$ & $\begin{array}{l}235[180-270] / \\
180[120-250]\end{array}$ & $\begin{array}{c}190 \\
{[157.5-252.5] /} \\
195 \\
{[125-255]}\end{array}$ & $<0.001 / 0.983$ \\
\hline $\begin{array}{l}\text { Intraoperative } \\
\text { bleeding } \\
\text { volume (mL) }\end{array}$ & $\begin{array}{c}200[100-350] / \\
100[50-200]\end{array}$ & $\begin{array}{c}200[100-400] / \\
100[50-250]\end{array}$ & $<0.001 / 0.186$ \\
\hline $\begin{array}{l}\text { Postoperative } \\
\text { stay (days) }\end{array}$ & $\begin{array}{c}14[9-21] / \\
8[6-10]\end{array}$ & $\begin{array}{c}11[8-29.5] / \\
8[7-12]\end{array}$ & $<0.001 / 0.01$ \\
\hline $\mathrm{CCl}$ & $\begin{array}{l}3[2-4] / \\
3[2-4]\end{array}$ & $\begin{array}{l}3[3-5] / \\
3[2-4]\end{array}$ & $0.001 / 0.05$ \\
\hline
\end{tabular}

ILD, interstitial lung disease; COPD, chronic obstructive pulmonary disease; VATS, video assisted thoracoscopic surgery; VAMT, video-assisted minithoracotomy; ASA, American Society of Anesthesiologists; FEV1, forced expiratory volume in $1 \mathrm{~s} ; \mathrm{CCl}$, Charlson comorbidity index.

( $\mathrm{P}=0.003)$, ILD $(\mathrm{P}<0.001)$, COPD $(\mathrm{P}=0.007)$, lobectomy $(\mathrm{P}<0.001)$, blood loss $(\mathrm{P}<0.001)$, CCI $(\mathrm{P}=0.049)$ as independent risk factors of postoperative morbidity (Table 6). There were differences in the following clinical factors between these two groups: age $(\mathrm{P}=0.010)$, ILD $(\mathrm{P}<0.001)$, ASA classification $(\mathrm{P}=0.017)$, and postoperative morbidity $(\mathrm{P}<0.001)$. Multivariate analysis revealed that ILD $(\mathrm{P}=0.006)$ and postoperative complications $(\mathrm{P}=0.012)$ were independent risk factors of 90-day mortality (Table 6).

Of the 1,309 patients, 9 died within 90 days postoperation, of which 5 died of AE-ILD, 2 died of pulmonary embolism, 1 died of myocardial infarction and 1 died of heart failure.

There were 6 patients of AE-ILD, all of whom had a history of ILD and were male. The age of these 6 patients ranged from 62 to 78 years old, with a median age of 
69.3 years old. The mean time of AE-ILD onset and time of death were 7.8 and 31 days postoperation, respectively. None of the patients received prophylactic steroid therapy, but steroid therapy was given after the diagnosis of AEILD. Only one patient them recovered from AE-ILD, and the other patients died within 90 days (Table 7).

\section{Discussion}

In this study, we found that patients with ILD presented a significantly higher incidence of postoperative morbidity and 90 -day mortality than those without ILD. As 55.6\% of 90-day deaths were caused by AE-ILD, AE-ILD could be recognized as a factor that leads to disastrous morbidity and

Table 6 Multivariate analysis to identify predictors of postoperative morbidity and 90-day mortality in patients with ILD

\begin{tabular}{lcrc}
\hline Accident & OR & $95 \% \mathrm{Cl}$ & $\mathrm{P}$ \\
\hline Morbidity & & & \\
Sex & 1.575 & $1.163-2.134$ & 0.003 \\
ILD & 2.354 & $1.479-3.745$ & $<0.001$ \\
COPD & 2.793 & $1.816-1.181$ & 0.007 \\
Lobectomy & 0.420 & $0.287-0.615$ & $<0.001$ \\
Blood loss & 0.999 & $0.999-1.000$ & $<0.001$ \\
CCl & 0.894 & $0.800-1.000$ & 0.049
\end{tabular}

Death within 90 days

$\begin{array}{lrrr}\text { ILD } & 8.268 & 1.829-37.382 & 0.006 \\ \text { complication } & 15.164 & 1.798-127.876 & 0.012\end{array}$

ILD, interstitial lung disease; OR, odds ratio; $\mathrm{Cl}$, confidence interval. should be treated immediately.

ILD is a progressive diffuse lung disease with poor prognosis (1), The incidence of ILD in the United States ranged from 6.8 to 16.3 per 100,000 people (11). It is less common in patients younger than 50 years old, and patients with ILD usually have a median survival of approximately $2-3$ years $(7,12)$. Increasing exposure of possible pathogenic factors such as smoking and secondhand smoking, environmental exposures and microbial factors could partially explain the higher incidence of ILD in elder patients (6). Similar to this finding, our results showed that age was an independent risk factor for ILD in surgical patients. We deduced that the incidence of ILD was increased with advancing age.

As reported in the literature, the postoperative morbidity and 90-day mortality rates in ILD patients were significantly higher than those in the non-ILD patients. AE-ILD, which is a rapidly progressive disorder in patients with ILD, has been reported to be the main factor of 90 -day mortality $(5,7,13,14)$.

Chiyo et al. believed that the incidence of pulmonary morbidity was significantly higher in ILD patients than in nonILD patients (9). Takeda and his colleagues found that the incidence of morbidity was greater in the ILD group than in the non-ILD group ( $\mathrm{P}=0.0004)$ (15). However, Voltolini et al.'s study showed different outcomes. In their study, ILD led to more acute respiratory distress syndrome/acute lung injury (ARDS/ ALI) postoperatively but not to other pulmonary complications, such as postoperative air leakage, pulmonary infection, pleural effusion and chylothorax (13). In our study, ILD was an independent risk factor for postoperative morbidity. ILD led to pulmonary fibrosis, weaken the healing ability of lung tissue and thus resulting in postoperative air leakage, and pleural effusion could be a possible explanation. Furthermore, change in the

Table 7 Clinical characteristics of patients who experienced AE-ILD

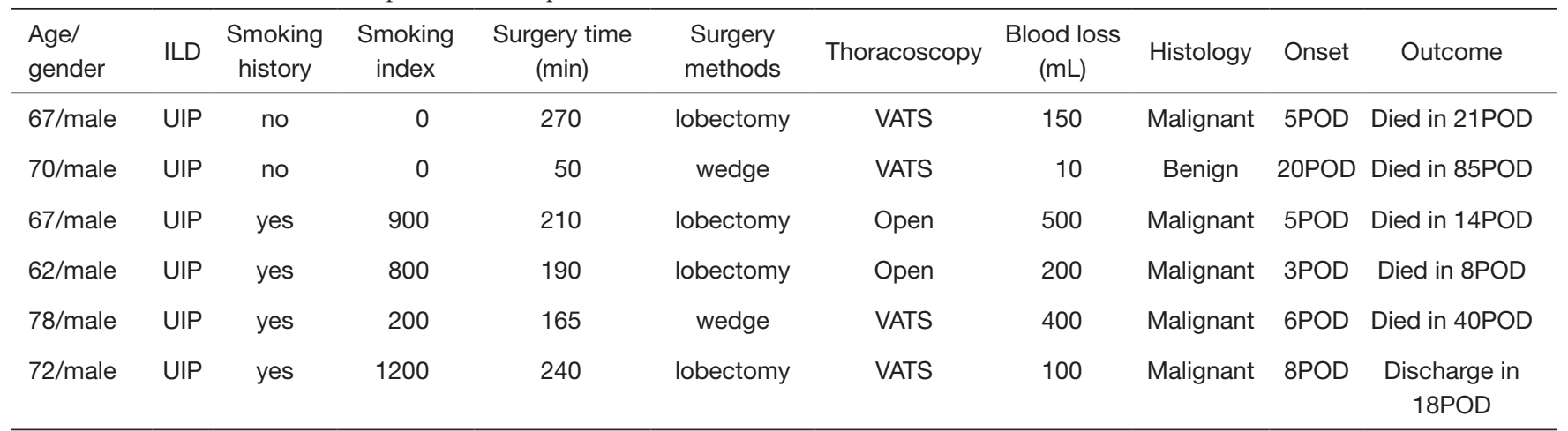

ILD, interstitial lung disease; UIP, usual interstitial pneumonia; VATS, video assisted thoracoscopic surgery; POD, post of operation. 
pulmonary interstitium might cause pulmonary hypertension, emphysema and obstructive sleep apnea, which in turn increased the risk of postoperative complications (6).

Chiyo et al. retrospectively analyzed 931 patients with lung cancer. Among them, 36 patients were diagnosed with ILD confirmed by HRCT/CT. The incidences of pneumonia and AE-ILD in these 36 patients was significantly higher than those in patients without ILD $(\mathrm{P}<0.05)$, but there was no significant difference in 30-day mortality between these two groups $(\mathrm{P}=0.30)$ (9). A large-scale multicenter cohort study from 61 hospitals in Japan reported that 164 (9.3\% of the 1,763 cases) ILD patients with lung cancer had AE-ILD after pulmonary surgery, with a mortality rate of $43.9 \%$. Approximately $71.7 \%$ of the deaths occurred within 30 days postoperation (7). In our study, postoperative morbidity and mortality were similar to those in previous studies; $9(0.7 \%)$ patients died within 90 days postoperation, and a total of 6 patients were diagnosed AE-ILD in the ILD group, of which 5 died of AE-ILD. Most published studies used the 30-day mortality rate as their primary outcome $(5,7,9)$. However, we found that two patients with AE-ILD died at 40 and 85 days after the operation. Three (3.1\%) patients died within 30 days of AE-ILD, and 5 (5.2\%) patients died within 90 days. Using a 30-day mortality rate would underestimate the short-term mortality rate; thus, the 90-day mortality rate could be a better alternative. A similar outcome has also been reported in Fukui et al.'s study (14).

Sato et al. found that the incidence of AE-ILD was 3.83 and 5.70 times higher in patients receiving lobectomy/ segmentectomy and combined lobectomy/pneumonectomy, respectively, compared with patients receiving wedge resection (5). Fujimoto et al. proposed that local resection should be performed if possible although it might increase the rate of tumor recurrence (16). In our study, surgical procedures did not differ between the ILD and nonILD groups, and different surgical procedures showed an influence on postoperative morbidity $(\mathrm{P}<0.001)$ but not on 90 -day mortality. While limited resection might decrease the postoperative morbidity, it might increase the recurrence rate and decrease the survival rate. Lobectomy should still be performed as the primary choice.

Long operation time, anesthesia time and one-lung ventilation time have been considered to induce oxygenfree radicals production, thus result in ARDS/AE-ILD postoperation (17). However, Fukui et al. studied the effect of operation time on lung cancer patients with ILD and found that the average operation time in the ILD and non-ILD groups was $184.8 \pm 84.3 \mathrm{~min}$ and $189.1 \pm 86.5 \mathrm{~min}$ $(\mathrm{P}=0.51)$, respectively. There was no significant difference of operation time between the $\mathrm{AE}$ group and the non-AE group $(\mathrm{P}=0.052)$ (14). Similar findings from the study of Omori et al. showed that the mean operation time in ILD and non-ILD patients were $291.7 \pm 78.2$ and $319.2 \pm 109.9$ min respectively $(\mathrm{P}=0.143)$ (18). In our study, the average operation time in the ILD group and the non-ILD group was 200 (IQR, 120267.5 ) $\mathrm{min}$ and 195 (IQR, 130-255) $\mathrm{min}(\mathrm{P}=0.700)$, and the anesthesia time was 260 (IQR, 175-320) $\mathrm{min}$ and 250 (IQR, 190-310) $\min (\mathrm{P}=0.955)$, respectively. ILD patients seemed to have longer operation times, whether a combination of ILD increases operation difficulty still needs further study.

As a feasible and safe surgical method, VATS has been widely used in the resection of early-stage lung cancer with an acceptable long-term survival rate (19). We found that there was no significant difference between the postoperative morbidity group and 90-day mortality group. According to the statistical results, we might conclude that surgical approach and non-lung injury (such as incision size) had no effect on postoperative morbidity and 90-day mortality.

The average blood loss in the ILD group and nonILD group was 200 (IQR, 100-400) mL and 100 (IQR, $50-250) \mathrm{mL}(\mathrm{P}=0.186)$, in the postoperative morbidity group and non-postoperative morbidity group was 200 (IQR, 100-350) $\mathrm{mL}$ and 100 (IQR, 50-200) $\mathrm{mL}(\mathrm{P}<0.001)$, and in the 90-day death group and 90-day nondeath group was 200 (IQR, 100-400) $\mathrm{mL}$ and 100 (IQR, 50-250) mL $(\mathrm{P}=0.186)$, respectively. we could see that there was a significant difference between the postoperative morbidity group and non-postoperative morbidity group. Maniwa $\mathrm{T}$ et al did not found a significant correlation between blood loss and ILD (20). However, Taniguchi et al. indicated that the blood loss in ILD patients suffering from acute exacerbation postoperation was greater than that in ILD patients without AE $(628 \pm 338.7 v s .272 .2 \pm 451.7 \mathrm{~mL}, \mathrm{P}=0.024)(21)$. We believed that combined with ILD would increase the difficulty of surgery, increase the operation time and blood loss, and might cause postoperative morbidity.

ASA classification was used in the anesthesiology department to evaluate the physical condition and surgical risk of patients (22). Marret et al. found that the ASA classification of III and IV correlated with poor outcome in patients receiving lobectomy $(\mathrm{P}<0.0001)(23)$. Similar findings from Limmer et al. showed that patients with an ASA classification of IV undergoing chest operation had a significantly higher mortality rate and longer hospitalization time $(\mathrm{P}=0.001)$ (24). Our results showed that there was a significant difference in ASA classification between the ILD group and the non-ILD group $(\mathrm{P}=0.005)$, and there 
was a significant difference in univariate analysis of 90-day mortality ( $\mathrm{P}=0.017)$, but there was no significant difference in multivariate analysis $(\mathrm{P}>0.05)$. Meanwhile, our results showed that there was a significant difference in ASA classification between AE-ILD group and non-AE-ILD group ( $\mathrm{P}=0.038)$. ILD can cause ASA classification upgrade and influence 90 -day mortality. We needed to pay attention to the ASA classification in the perioperative period.

CCI is commonly used to predict the mortality rate of patients with chronic diseases according to the assessment of physical function. ILD impairs cardiopulmonary function and thus increased the risk of perioperative mortality (25). In our study, the CCI in the ILD and non-ILD groups were 3 (IQR, $2-4)$ and 3 (IQR, 2-4) $(\mathrm{P}<0.001)$, respectively, which might be due to the increase in CCI indirectly caused by ILD. The average CCI in the postoperative morbidity group and nonpostoperative morbidity group was 3 (IQR, 2-4) and 3 (IQR, $2-4)(\mathrm{P}=0.049)$, respectively. This finding suggested that CCI adversely affects postoperative morbidity, and we should pay attention to CCI in clinical practice.

Most studies of the lung function test focused on FEV $1 \%$ and DLCO\%. Luca Voltolini et al. reported that the FEV1 \% and DLCO\% in ILD and non-ILD patients were $88.8 \% \pm 12.3 \%$ vs. $84.1 \% \pm 0.4 \%(\mathrm{P}>0.05)$ and $59.13 \% \pm 14.34 \%$ vs. $65.53 \% \pm 19.20 \%(\mathrm{P}>0.05)$, respectively. However, approximately $50 \%$ of ILD patients with FEV1 $\%$ less than $80 \%$ developed ARDS/ALI after surgery, while no ILD patients with FEV1 \% greater than $90 \%$ suffered from ARDS/ALI (13). Fukui et al. reported that FEV1\%, VC\% and DLCO \% in the ILD and non-ILD group were $74.8 \% \pm 0.7 \%$ vs. $74.9 \% \pm 0.3 \%(\mathrm{P}=0.88), 94.4 \% \pm 17.7 \%$ vs. $97.3 \% \pm 15.9 \%(\mathrm{P}=0.028)$ and $48.2 \pm 1.2$ vs. $64.5 \pm 0.5$ $(\mathrm{P}<0.001)$, respectively. The value of $\mathrm{VC} \%$ and $\mathrm{DLCO} \%$ was significantly different between the ILD group and the non-ILD group (14). In our study, the analysis of DLCO and VC was not performed because of a shortage of medical resources and medical insurance. According to whether FEV1/FVC was less than 0.7 as a cutoff point, we found that there was no significant difference between the ILD group and the non-ILD group $(\mathrm{P}=0.859)$. The average values of $\mathrm{FEV} 1 \%$ predict in the ILD and non-LID groups were $77.7 \%$ (IQR, 73.12-79.95\%) and 78.1\% (IQR, 74.51$80.66 \%)$ respectively $(\mathrm{P}=0.452)$. We concluded that FEV1\% predict had little influence on ILD.

Several limitations should be noted in this study. First, as a retrospective study, it is vulnerable to various sources of deviation that might not be identified and controlled. Second, this was a single institutional study with a limited sample size and thus calls for more evidence from further prospective studies (including a larger series of patients). Finally, all patients in this study were Chinese. Some studies have shown that there were racial differences in the frequency of ILD and AE-ILD (26).

In conclusion, patients with ILD had a higher incidence of postoperative morbidity and 90-day mortality. ASA classification is an important influencing factor of AE-ILD. AE-ILD could lead to a significantly higher mortality rate. Special attention and management should be given to ILD patients when undergoing pulmonary operation. Based on our clinical experience, steroid therapy was an alternative method for AE-ILD. Hence, when an ILD patient is undergoing surgery, the patient needs to be evaluated jointly by a thoracic surgeon, a respiratory surgeon, and an anesthesiologist.

\section{Acknowledgments}

Funding: None.

\section{Footnote}

Conflicts of Interest: The authors have completed the ICMJE uniform disclosure form (available at http://dx.doi. org/10.21037/tcr.2019.12.88). The authors have no conflicts of interest to declare.

Ethical Statement: The authors are accountable for all aspects of the work in ensuring that questions related to the accuracy or integrity of any part of the work are appropriately investigated and resolved. The patients underwent surgery after providing informed consent, and the requirement for the individual consent of patients whose records were evaluated was waived because they were de-identified in the study. The study was approved by institutional ethics board of China-Japan Friendship Hospital (No. 2018-13-K08).

Open Access Statement: This is an Open Access article distributed in accordance with the Creative Commons Attribution-NonCommercial-NoDerivs 4.0 International License (CC BY-NC-ND 4.0), which permits the noncommercial replication and distribution of the article with the strict proviso that no changes or edits are made and the original work is properly cited (including links to both the formal publication through the relevant DOI and the license). See: https://creativecommons.org/licenses/by-nc-nd/4.0/. 


\section{References}

1. Wallis A, Spinks K. The diagnosis and management of interstitial lung diseases. BMJ 2015;350:h2072.

2. Lynch DA, Lynch JP, King T, et al. American Thoracic Society. Idiopathic pulmonary fibrosis: diagnosis and treatment. International consensus statement. American Thoracic Society (ATS), and the European Respiratory Society (ERS). Am J Respir Crit Care Med 2000;161:646-64.

3. Harris JM, Johnston ID, Rudd R, et al. Cryptogenic fibrosing alveolitis and lung cancer: the BTS study. Thorax 2010;65:70-6.

4. Daniels CE, Jett JR. Does interstitial lung disease predispose to lung cancer? Curr Opin Pulm Med 2005;11:431-7.

5. Sato T, Watanabe A, Kondo H, et al. Long-term results and predictors of survival after surgical resection of patients with lung cancer and interstitial lung diseases. J Thorac Cardiovasc Surg 2015;149:64-9, 70.e1-2.

6. Raghu G, Collard HR, Egan JJ, et al. An official ATS/ ERS/JRS/ALAT statement: idiopathic pulmonary fibrosis: evidence-based guidelines for diagnosis and management. Am J Respir Crit Care Med 2011;183:788-824.

7. Sato T, Teramukai S, Kondo H, et al. Impact and predictors of acute exacerbation of interstitial lung diseases after pulmonary resection for lung cancer. J Thorac Cardiovasc Surg 2014;147:1604-1611.e3.

8. Navaratnam V, Fleming KM, West J, et al. The rising incidence of idiopathic pulmonary fibrosis in the U.K. Thorax 2011;66:462-7.

9. Chiyo M, Sekine Y, Iwata T, et al. Impact of interstitial lung disease on surgical morbidity and mortality for lung cancer: analyses of short-term and long-term outcomes. J Thorac Cardiovasc Surg 2003;126:1141-6.

10. Hyzy R, Huang S, Myers J, et al. Acute Exacerbation of Idiopathic Pulmonary Fibrosis. Chest 2007;132:1652-8.

11. Raghu G, Weycker DJ, Bradford WZ, et al. Incidence and prevalence of idiopathic pulmonary fibrosis. Am J Respir Crit Care Med 2006;174:810-6.

12. Guiot J, Corhay JL, Louis R. Idiopathic pulmonary fibrosis. Rev Med Liege 2014;69:605-10.

13. Voltolini L1, Bongiolatti S, Luzzi L, et al. Impact of interstitial lung disease on short-term and long-term survival of patients undergoing surgery for non-small-cell lung cancer: analysis of risk factors. Eur J Cardiothorac Surg 2013;43:e17-23.

14. Fukui M, Suzuki K, Oh S, et al. Distribution of interstitial pneumonia: a new radiological predictor of 90-day mortality after resection of lung cancer. Surgery Today 2016;46:66-73.
15. Takeda S, Maeda H, Sawabata N, et al. Clinical impact of interstitial pneumonia following surgery for lung cancer. Thorac Cardiovasc Surg 2006;54:268-72.

16. Fujimoto T, Okazaki T, Matsukura T, et al. Operation for lung cancer in patients with idiopathic pulmonary fibrosis: surgical contraindication? Ann Thorac Surg 2003;76:1674-8.

17. Misthos P, Katsaragakis S, Milingos N, et al. Postresectional pulmonary oxidative stress in lung cancer patients. The role of one-lung ventilation. Eur J Cardiothorac Surg 2005;27:379-82.

18. Omori T, Tajiri M, Baba T, et al. Pulmonary Resection for Lung Cancer in Patients With Idiopathic Interstitial Pneumonia. Ann Thorac Surg 2015;100:954-60.

19. Kim K, Hong KK, Park JS, et al. Video-Assisted Thoracic Surgery Lobectomy: Single Institutional Experience With 704 Cases. Ann Thorac Surg 2010;89:S2118-22.

20. Maniwa T, Isaka M, Nakagawa K, et al. Chest-tube drainage is a sign of acute exacerbation of interstitial lung disease associated with lung cancer. Surgery Today 2013;43:408-11.

21. Taniguchi D, Yamasaki N, Miyazaki T, et al. The surgical outcomes of lung cancer combined with interstitial pneumonia: a single-institution report. Surg Today 2017;47:1397-404.

22. Eakin JL, Bader AM. ASA physical status classification system: Is it consistent amongst providers and useful in determining need for pre-operative evaluation resources? J Clin Anesth 2017;39:73-4.

23. Marret E, Miled F, Bazelly B, et al. Risk and protective factors for major complications after pneumonectomy for lung cancer. Interact Cardiovasc Thorac Surg 2010;10:936-9.

24. Limmer S, Hauenschild L, Eckmann C, et al. Thoracic surgery in the elderly--co-morbidity is the limit. Interact Cardiovasc Thorac Surg 2009;8:412-6.

25. Laor A, Tal S, Guller V, et al. The Charlson Comorbidity Index (CCI) as a Mortality Predictor after Surgery in Elderly Patients. Am Surg 2016;82:22-7.

26. Azuma A, Hagiwara K, Kudoh S. Basis of acute exacerbation of idiopathic pulmonary fibrosis in Japanese patients. Am J Respir Crit Care Med 2008;177:1397-8; author reply 1398.

Cite this article as: Shao W, Huang J, Feng H, Sun H, Ren Y, Wang X, Zhang Z, Liu D. Impact of interstitial lung disease on postoperative morbidity and 90-day mortality after pulmonary resection. Transl Cancer Res 2020;9(2):1151-1159. doi: $10.21037 /$ tcr.2019.12.88 